\title{
The KwaZulu-Natal Child Eye Care Programme: Delivering refractive error services to primary school learners*
}

\author{
YI Maharaj ${ }^{a, c}$, KS Naidoo ${ }^{a, b, c}$, R Dabideen ${ }^{a, c}$ and P Ramson ${ }^{a, b, c}$
}

aDiscipline of Optometry, School of Physiotherapy, Sport Science and Optometry, University of KwaZulu-Natal, Durban, 4000 South Africa

${ }^{\mathrm{b}}$ The International Centre for Eye Care Education (ICEE)

${ }^{\mathrm{c}}$ The African Vision Research Institute (AVRI)

Received 6 August 2010; revised version accepted 16 May 2011

\begin{abstract}
Globally, over 300 million people are estimated to be visually impaired. Uncorrected refractive error is the primary cause of almost half of all visual impairment, resulting in the global economy losing $\$ 269$ billion in productivity annually. There is a definitive level of urgency in the treatment of refractive error in children as uncorrected refractive error results in the failure of normal visual maturation, termed amblyopia, which cannot be corrected in adult life. In South Africa, the lack of appropriate child eye care strategies has posed a serious problem to the visual health of children. In 2006, the International Centre for Eye Care Education (ICEE) conducted a situational analysis of child eye care services in the province of KwaZulu-Natal (KZN). The findings of this analysis indicated a dire need for comprehensive services in the province. Stakeholders (the KwaZulu-Natal Department of Health and the KwaZulu-Natal Department of Education) were advised on the value of a short-term strategy as the underpinning of a long-term sustainable approach. This resulted in the formation of a tri-
\end{abstract}

alliance to implement the KZN Child Eye Care Programme. Eighty (80) individuals who were previously volunteers for the KZN Department of Health were trained in vision screening. These vision screeners screened 239606 primary school children from February 2007 to May 2008. Seven percent (15 944) of the children failed the vision screening and were referred for optometric assessments. Of the 15944 children that failed the vision screening, 10707 children were examined by optometrists and 1083 were found to have a refractive error and were therefore supplied with spectacles. The study indicates that a short-term programme to address a backlog of services can reach many underserved children. This programme identified many challenges of implementing a vision screening programme such as poor uptake of refractive services by learners in the absence of an appropriate referral system and high attrition of trained vision screeners. (S Afr Optom 2011 70(2) 61-68)

Key words: Refractive error, visual acuity, vision screening, vertical approach, interdepartmental collaboration

* This paper forms part of research undertaken for the degree of Master in Optometry (MOptom) at the University of KwaZuluNatal undertaken by YI Maharaj with the supervision of Professor KS Naidoo 


\section{Introduction}

Globally, about 314 million people are visually impaired ${ }^{1}$. Uncorrected refractive error is the primary cause of almost half of all visual impairment; the second leading cause of blindness after cataract; and the main cause of low vision ${ }^{1}$. Refractive error represents a substantial public health challenge in many parts of the developing world ${ }^{1}$. The global economy loses about $\$ 270$ billion in productivity annually due to uncorrected refractive error ${ }^{2}$. Ironically, refractive error is one of the simplest eye conditions to diagnose and measure, with the most cost-effective intervention being a pair of spectacles.

The correction of reduced vision in children poses particular challenges which are different from the challenges of correcting reduced vision in adults. Children are born with an immature visual system and for normal visual development to occur, they need clear, focused images to be transmitted to their higher visual centers. Failure of normal visual maturation, termed amblyopia, usually cannot be corrected in adult life hence there is a definitive level of urgency in the treatment of reduced vision in children ${ }^{3}$. Blindness in childhood has far reaching implications for the affected child and their family as it influences educational, employment, personal and social prospects ${ }^{3}$. Vision screening, appropriate referrals and the management of visual conditions of children should therefore be a priority in public health and education systems. The global financial cost of blindness with an onset during childhood, in terms of loss of earning capacity (per capita Gross National Product), is greater than the cost of adult onset blindness ${ }^{3}$. These financial costs alone, however, provide only one perspective of the public health burden of uncorrected vision.

The Alma Ata Declaration ${ }^{4}$ of 1978 placed emphasis on Primary Health Care, the need for early detection and the decisive treatment of potentially life-threatening conditions. This would be done through screening which is the systematic search to identify people who are unaware that they have a condition or people who are considered to be at high-risk of developing a specific disease, defect or significant deviation ${ }^{5}$. According to the World Health Organisation's recommendations for health related screening programmes, detecting ocular disorders in children are important as they can present a serious health problem. Ocular disorders can be detected via reliable diagnostic tests that are available; therefore the effective treatment of ocular disorders is possible 6 .

Many studies have indicated the need for appropriate refractive error testing and its correction in children $^{7-10}$. Ayed et al (2002) showed a significant association between refractive errors and academic failure in children from poor areas. They concluded that the ability of a child to participate in the educational experience is partially dependent on good vision ${ }^{7}$. Their conclusion is corroborated by Gruning (2001) who reported that vision problems may not be the direct cause of learning disorders, but they can interfere with a child's ability to perform to his full potential in life ${ }^{8}$. Leat et al (1999) reported that at the end of a 35 year study period, better surveillance and health education led to all suspected congenitally blind children being identified before the age of two years ${ }^{9}$. Prior to the implementation of routine surveillance, only one half had been identified by this age which indicates that the presence of a system can improve identification and without it, serious handicaps can be neglected and remains undetected ${ }^{9}$. The Hall Report in Britain recommended vision screening at 21 and 39 months, and again at 5, 8 and 11 years ${ }^{9}$.

In South Africa, the lack of appropriate child eye care strategies has posed a serious problem to the visual health of children. Of particular concern is the need to merge the efforts of different government departments into a coherent strategy that is sustainable. The Refractive Error Study in School Children - Africa (RESCA) ${ }^{10}$ conducted in Durban, South Africa, 2003 , found that of those children with reduced vision, $63 \%$ was due to uncorrected refractive error. In addition, only $20 \%$ of the children that needed spectacles had them, indicating that four out of every five children with vision problems are needlessly visually impaired or blind ${ }^{10}$.

As signatories to the Convention on the Rights of the Child, the South African Government has pledged to 'put children first' and give their needs the highest priority ${ }^{11}$. In practice, that would translate to ensuring that children's rights are upheld and that an enabling environment is created for them to develop to their full potential. South Africa has a relatively developed infrastructure. However due to the inequities in health delivery under the previous political dispensation, health services and eye care in particular, have been 
heavily skewed to the private health sector and offered mainly in urban areas. The National Department of Health estimates that approximately 37.4 million South Africans ( $85 \%$ of the population) depend upon public health sector services ${ }^{12}$. Of these, 13 million are children under the age of 16 years ${ }^{12}$; indicating that the majority of South African children have extremely limited access to any form of eye care services. The Health Professionals Council of South Africa indicates that there are currently 2500 optometrists in South Africa providing refractive error services to 44 million South Africans and only 70 of these optometrists $(3 \%)$ are employed full-time in the public health sector; a ratio of one optometrist per 543000 population. This ratio falls far short of international norms with countries such as the United Kingdom having ratios of 1: $5200 .{ }^{13}$

The District Health System (DHS) has been implemented in all nine provinces, with services provided from the Primary Health Care (PHC) level to the specialist Tertiary Hospitals ${ }^{14}$. The National Department of Health is committed to Vision 2020: The Right to Sight, a global initiative for the elimination of avoidable blindness; with task forces being established at all levels. National guidelines exist but the level of implementation varies between provinces and districts. Children first make contact with the health system at birth, after 18 months, and when the last scheduled immunization is delivered ${ }^{11}$. Thereafter, contact with the health system is made again when they receive their five year booster vaccine, become ill or need reproductive care in their teens. However, for various reasons, many pre-school children do not benefit from the health services they should be accessing. Activities such as screening to identify developmental and other barriers to learning are often not implemented. As a result, many children enter the formal education system with unidentified health problems which impact on their ability to learn effectively. Children are in school for 40 weeks per year over a 13 year period, during which time they are a captive audience for health education and interventions that will influence their health status and practice. Once educated, children can potentially become conveyors of health information and models of healthy behaviour for their families and the broader community ${ }^{11}$.

A number of approaches to develop appropriate human resources to deliver health care services have been developed. While the general trend has been in the direction of comprehensive and integrated health systems, some programmes have had a single focus as in a 'Vertical System'. Miller (2005) states that the vertical approach is a call for a solution of a given health problem by means of a single-purpose specialized service tool that is used to direct, supervise and execute the approach via enthusiastic health workers ${ }^{15}$

Given the historical effectiveness of the vertical approach in addressing high volumes of patients, the International Centre for Eye Care Education (ICEE) proposed the KwaZulu-Natal Child Eye Care Programme: a vertical approach to addressing refractive error in the province, which is the training of a special cadre of vision screeners. This approach was viewed as a quick short-term strategy whilst the long-term strategy for an integrated approach for maintaining optimal levels of vision screening amongst primary school children was being developed (using the information and lessons from the short-term strategy).

The provision of infrastructure by schools, affords the opportunity for health and other social services to collaborate with educators in addressing children's health, developmental and social needs ${ }^{11}$. Screening can be implemented in schools as good vision is important for education, and with education being mandatory, it is easy to reach all children of a given age. Furthermore, schools are increasingly being viewed as providing a supportive environment where children can develop healthy attitudes and practices, with vision screening falling within this rationale ${ }^{11}$. This paper, therefore discusses the effective delivery of refractive error services to primary school learners, with particular focus on the results of the ICEE vertical approach.

\section{Methodology}

In 2006, ICEE conducted a situational analysis of child eye care services in the province of KwaZuluNatal (KZN). The findings of this analysis indicated a dire need for comprehensive services in the province. In keeping with ICEE's strategy to improve eye care service delivery, ICEE drafted a Programme Charter that discussed the current state of child eye care in the province and proposed a programme called the KZN Child Eye Care Programme. The objectives of this 
programme were to:

1. Address the current back-log of refractive error services to all primary school children in KZN.

2. Develop capacity in the Public Sector to deliver ongoing refractive error services to primary school children.

3. Develop a model / guidelines to deliver refractive error services to primary school children with a view to rolling it out nationally.

Identifying the Department of Education and the Department of Health as key stakeholders, ICEE engaged in stakeholder education on blindness prevention with special attention to children with uncorrected refractive error. Stakeholders were advised on the value of a short-term strategy as the underpinning of a long-term sustainable approach. They were also briefed on the need to integrate the efforts of the Education and Health Departments. Successful meetings were held with the relevant Heads of Department, which were based on their willingness to support the programme. The willingness from the Heads of Department was due to their realisation that current resources were inadequate to address refractive error in children. They also appreciated the need for a concerted, coordinated and collaborative effort by civil society as well as government. Following the signing of the Memorandum of Understanding, a Task Team with representatives from all three organisations was formed to further plan, implement, monitor and evaluate the programme. To devolve the plans of the KZN Child Eye Care programme, the Task Team conducted an awareness programme across the province wherein District Managers from both the Health and Education Departments were briefed on the programme. It also provided a forum for discussion and related broad planning. These meetings occurred over a period of four months (from August 2006 to November 2006).

\section{Identifying Programme Implementation Areas}

Planning the programme depended on accurately locating all primary school and health facilities in the province. As such, data sets of primary schools and health facilities were obtained from the Department of Education and the Department of Health respectively. These were combined to generate district level maps containing all primary schools and their closest health facilities that offered eye care services. Schools which were further than 60 kilometers away from the closest health facility were clustered and prioritized for project implementation as all stakeholders accepted that not all schools could be assessed with the resources available within the project, and that it made sense to reach those children that were least likely to have their eyes examined.

Vision Screeners - Selection; Training and Implementation

In adherence to a vision screening protocol (Figure 1), 80 individuals were selected for training in vision screening. Individuals were selected by the Department of Health out of their volunteer base. The number of screeners selected per district was based on the number of schools within that district. All vision screeners underwent a five day training course that was designed and conducted by ICEE. The vision screeners received training in anatomy of the eye, visual acuity measurement, refractive error correction and ocular pathology

A competency exam was held on the last day of the training programme to assess the screener's ability to screen effectively. Once certified to be competent in vision screening, vision screeners received a list of the schools for which they were responsible. Project administrators who were office-based communicated with vision screeners on their mobile phones on a daily basis to assess their daily progress. Since large numbers of children were to be screened, vision screeners utilised The Wheel of Vision - compact vision screening device containing an occluding lens, 2 D lens and pinhole lens. For older children, a Snellen Chart was utilized, whereas for younger children, an Illiterate E Chart was used.

All recording sheets utilised by the vision screeners were designed with a view to minimise writing on their part and save time, hence, where possible tick boxes were used. Once a vision screener completed screening at a school, referral letters for those children that failed the vision screening were given to the school principal. This ensured that principals were fully informed of which children required further treatment; with the letter itself informing parents of what steps needed to be taken to access further services. All children that passed were also provided a letter that informed their care giver that they had passed the vision screening assessment. 


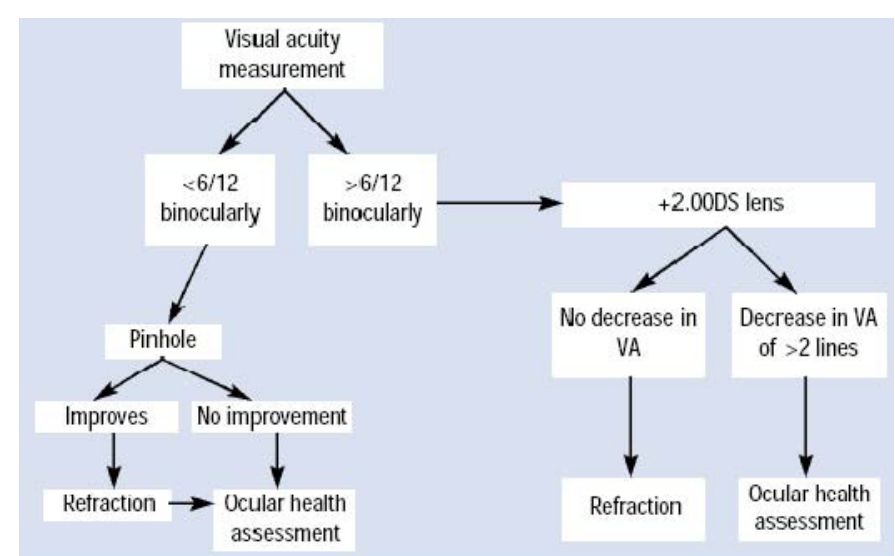

Figure 1 Vision Screening Protocol as adopted from Naidoo and Govender ${ }^{16}$

\section{Optometric Examinations}

All schools selected were provided with a name of a clinic or hospital that their learners could attend in order to receive a comprehensive eye examination. Based on the researchers' experiences in the public sector, many clinics have booking procedures in place with an average waiting period of about three months. To fast track services to the learners, the Department of Health issued a directive to all its eye clinics to allow learners to be prioritised for an appointment if they could not be seen on the very day that they presented to the clinic. In addition, the hospital admission fee was waivered when learners produced the official KZN Child Eye Care Programme Referral letter - an incentive to improve uptake of refractive services. Once at the clinic, the consulting optometrist assessed the learner's visual acuity at distance and near, conducted all near function tests, pupil tests, cyclocloplegic autorefraction and retinoscopy, as well as a subjective refraction if required.

Initially, recording sheets were provided to all public sector optometrists. They were asked to complete this record card and forward it to ICEE so that the data of all learners refracted could be entered into a data base. However, optometrists were not compliant in this regard and if a child required spectacles, the procedure was reduced to only the spectacle order being sent to ICEE. Detailed clinical records of the child were thus kept with the optometrist at the site of examination.

Spectacles were provided free of charge if hyperopia was more than $2 \mathrm{D}$, myopia was more than $0.50 \mathrm{D}$ or astigmatism was greater than 0.75 D. ${ }^{16}$ Children were allowed to choose a frame from a range of plastic and metal frames that were provided to all optometrists. Once spectacles were manufactured, they were sent back to the optometrist for dispensing to the child. The turn around period was usually three weeks. An evaluation of children's satisfaction with the spectacles was not part of this study.

During the implementation of the programme, the number of optometric eye examinations occurring was significantly less than the number referred, indicating a poor uptake of refractive services from children that were referred. This was most likely due to the fact that most learners were from disadvantaged backgrounds with little or no funds available for the transport to the clinic. Consequently, additional measures were put in place to increase the access of optometric services by the learners. A Mobile Eye Clinic fully equipped with all optometric equipment and lens cut and fit equipment was sponsored by NISSAN South Africa. The Mobile Eye Clinic vehicle was then used to deliver optometric services in rural areas, where children had found it difficult to access refractive services. In the peri-urban areas, locum optometrists visited schools directly when screening was completed to examine those children that had failed the vision screening.

\section{Results}

\section{Vision Screening}

A total of 239606 primary school children were screened by vision screeners between February 2007 and May 2008, as indicated in Table 1. Given that KZN has a population of approximately 2.5 million primary school children ${ }^{12}$, the programme reached $9.41 \%$ of them. Table 2 indicates the number of primary schools screened per Health District. Assuming that the outcome is measured in terms of schools screened, the programme penetrated $18 \%$ of schools in the province.

The average number of children screened per vision screener was 2761 per screener. It is interesting to note that the collective output per district correlates better with the number of vision screeners retained rather than the number of vision screeners trained (Table 3). There was a high drop out of vision screeners over the entire period of the programme due to many of the vision screeners finding better employment opportunities or studying opportunities. 
Table 1 Children screened per health district

\begin{tabular}{|lccc|}
\hline \multicolumn{1}{|c}{ District } & No of Children & No screened & \% Learners \\
Ethekwini & 642316 & 44340 & 6.90 \\
Amajuba & 125252 & 10543 & 8.42 \\
Ilembe & 156338 & 15321 & 9.80 \\
Sisonke & 147787 & 10626 & 7.19 \\
Ugu & 204688 & 15573 & 7.61 \\
Umgungundlovu & 222250 & 27866 & 12.54 \\
Umkhanyakhude & 189004 & 22747 & 12.04 \\
Umzinyathi & 156269 & 33656 & 21.54 \\
Uthukela & 193004 & 22789 & 11.81 \\
Uthungulu & 257086 & 20207 & 7.86 \\
Zululand & 251393 & 15938 & 6.34 \\
& $\mathbf{2 5 4 5 3 8 7}$ & $\mathbf{2 3 9 6 0 6}$ & 9.41 \\
\hline
\end{tabular}

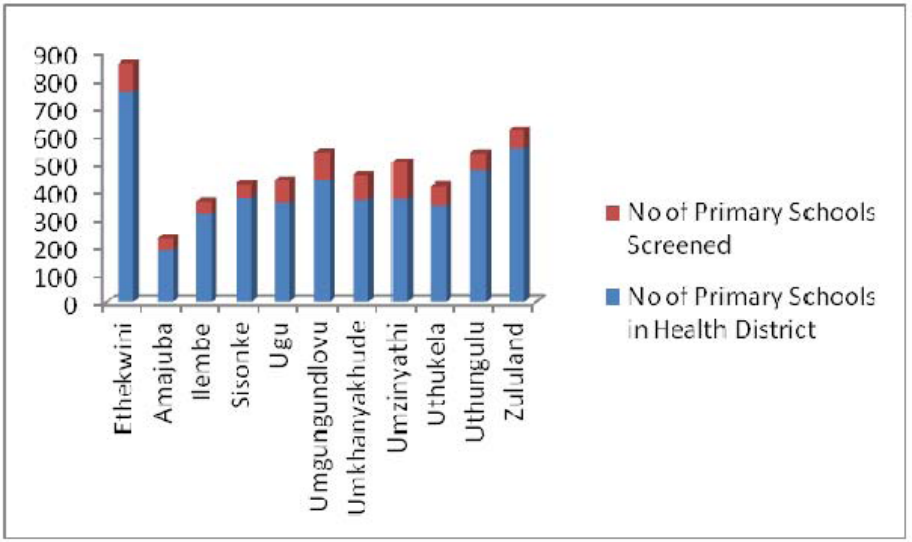

Figure 2 Number of primary schools screened per health district

Table 2 Vision Screener Retention rate and average output

\begin{tabular}{|c|c|c|c|c|c|c|}
\hline District & $\begin{array}{l}\text { Area } \\
\text { Type }\end{array}$ & $\begin{array}{c}\text { No } \\
\text { screened }\end{array}$ & $\begin{array}{l}\text { No of vision } \\
\text { screeners } \\
\text { trained }\end{array}$ & $\begin{array}{c}\text { No of } \\
\text { vision } \\
\text { screeners } \\
\text { remaining }\end{array}$ & $\begin{array}{c}\% \text { Vision } \\
\text { Screeners } \\
\text { Retained }\end{array}$ & $\begin{array}{c}\text { Average } \\
\text { learners } \\
\text { screened } \\
\text { per } \\
\text { screener }\end{array}$ \\
\hline Umzinyathi & Rural & 33656 & 9 & 8 & 89 & 3740 \\
\hline Umgungundlovu & $\begin{array}{l}\text { Peri- } \\
\text { Urban }\end{array}$ & 27866 & 8 & 7 & 88 & 3483 \\
\hline Ethekwini & Urban & 44340 & 11 & 9 & 82 & 4031 \\
\hline Amajuba & Rural & 10543 & 5 & 4 & 80 & 2109 \\
\hline Uthukela & Rural & 22789 & 8 & 6 & 75 & 2849 \\
\hline Umkhanyakhude & Rural & 22747 & 7 & 5 & 71 & 3250 \\
\hline Zululand & Rural & 15938 & 7 & 5 & 71 & 2277 \\
\hline Ilembe & $\begin{array}{l}\text { Peri- } \\
\text { Urban }\end{array}$ & 15321 & 6 & 4 & 67 & 2554 \\
\hline Ugu & $\begin{array}{l}\text { Peri- } \\
\text { Urban }\end{array}$ & 15573 & 7 & 3 & 43 & 2225 \\
\hline Uthungulu & Rural & 20207 & 8 & 3 & 38 & 2526 \\
\hline Sisonke & Rural & 10626 & 8 & 3 & 38 & 1328 \\
\hline
\end{tabular}

\section{Referral Rate}

Of the 239606 children screened, 15944 (7\%) failed the vision screening and were referred for optometric assessments. According Naidoo and Govender $^{16}$ (2002), children should be referred if:

1. They had a binocular visual acuity of less than $6 / 12$ but improvement in visual acuity with a pinhole lens.

2. They had a visual acuity of $6 / 12$ and better, but no blurring of vision with a $2 \mathrm{D}$ lens.

Children with tropias, red eyes or other obvious

3. pathology.

The referral rate per area type was averaged, and it was found that the rate was higher in urban areas $(11 \%)$ than in peri-urban $(6 \%)$ or rural areas $(6 \%)$. This was most likely due to better access in urban areas.

\section{Optometric Results}

Of the 15944 children that failed the vision screening, 10707 children were examined by optometrists. It is important to note that $3529(33 \%)$ children made the trip to their local health facility and were examined by optometrists within the Department of Health. The balance of children (7178) were examined by locum optometrists who made visits to their school or by the optometrist on board the Nissan Mobile Eye Clinic that visited their school.

\section{Refraction Findings}

One thousand eight hundred and three learners (1803) examined (16.8\%) were diagnosed with refractive error. These learners were provided with spectacles free of charge. There proved to be a high rate of false positive results for refractive error as the probability of a child who was referred to be diagnosed with refractive error was 0.17 . This value was small due to the large number of children referred for vernal conjunctivitis. Neither the recording sheets nor the data base were designed to separate refractive error and gross pathology data. As such, the false positive value and positive predictive value are skewed with data from gross pathology. False negatives were not calculated in the project due to the lack of resources. 


\section{Discussion}

Looking at the number of children screened per Health District, screening can be more easily conducted in urban and peri-urban areas. Ugu and Ilembe are peri-urban areas that did not perform well comparatively, however this can be attributed to the small number of screeners that were retained post-training (only three and four off six and seven respectively). Vision screeners from Umzinyathi, a rural area, screened the second highest number of children per district. This is attributed to the fact that the vision screeners in Umzinyathi were exceptionally well supervised by the Department of Health who held regular meetings with them to discuss their challenges and assist them where possible. Overall, it can be noted that whilst more children can be screened in urban and peri-urban areas, vision screeners in rural areas can achieve comparably if they are properly supported by local partners.

Amongst the other rural areas, poor access to schools (gravel roads with no public transport) was the main reason for their poor output. In many cases, vision screeners had to walk three to five kilometers to reach the school that they were screening, often reaching the school after 9.00am. Given that schools closed at $1.00 \mathrm{pm}$, the amount of time left for screening was not sufficient to generate the outcomes initially planned. Many rural schools run Feeding and Nutrition Schemes during school hours. This further decreases the screening time available. It should be noted that schools do not permit vision screening during the quarterly examination periods.

Seven percent (15 944) of the screened children failed the vision screening and were provided with hospital referral letters. It was originally planned that all children would be referred to the closest Department of Health Eye Clinic to be examined by the optometrist on duty, however many challenges were faced in this regard. Despite all optometrists being invited to a meeting informing them about the programme, many felt that consultation was not sufficient and did not examined children referred from the screening programme as agreed upon. In addition, they did not fill in the required hard copy forms, but only the spectacle order for children that did require spectacles. Thus, only spectacle information of children examined were available.
Further, optometrists indicated that very few learners reported to the hospital for an eye examination despite the large number of learners being screened in their respective health district. School principals were contacted to confirm the numbers of children that did access services. Principals re-affirmed that children had not accessed services. Reasons cited were lack of funds to travel to the hospital which in most cases were more than 60 kilometers away and a lack of interest from the care givers. It is interesting to note that only $37 \%$ of children received eye examinations at a Department of Health Eye Clinic. The other 67\% were examined on board the Nissan Mobile Eye Clinic or by locum optometrists at their school. It appears that for children, services need to be delivered as close as possible to them, that is, at their school.

\section{Conclusion}

Implementing a child eye care programme requires careful planning and must be aligned with the Department of Education and the Department of Health's strategic plan. Given the current backlog of services and poor eye care infrastructure; there needs to be short, medium and long-term approaches to addressing the problem. The KZN Child Eye Care Programme utilised a vertical approach which proved to be an effective strategy of reaching a large number of children in a short time period. In the long-term however, vision screening needs to carve its place within school health services; ensuring that all children are screened on entry to primary school and on exit of primary school. It therefore becomes important to build upon current practices to achieve the optimal level of service delivery.

A short-term programme to address a backlog of services can reach many underserved children. This programme identified many challenges of implementing a vision screening programme which in this case is compounded by an inter-department collaboration. A situation as such demands thorough consultation, planning and implementation. Furthermore, the utilisation and retention of vision screeners is influenced not only by the skill levels of the screeners or the training but also the remuneration and appropriate selection of screeners. Monitoring of outcomes is important, which therefore dictates that the appropriate data collection tools are developed. 


\section{Acknowledgements}

The authors would like to express appreciation to everyone that participated in this study as well as gratefully acknowledge the technical assistance provided from the African Vision Research Institute (AVRI).

\section{References}

1. Developing an action plan to prevent blindness at national, provincial and district levels - 2004 [CD-ROM], 2nd edition. Available from WHO, Genev, 2004.

2. Smith TST, Frick KD, Holden BA, Fricke TR and Naidoo KS. Potential lost productivity resulting from the global burden of uncorrected refractive error. Bulletin of the World Health Organisation 200987 431-437.

3. Management of Low Vision in Children - Report of a WHO Consultation, Bangkok, July 1992.

4. www.who.int/hpr/NPH/docs/declaration_almaata.pdf.

5. Wormald, R. Epidemiology in Practice: Screening for eye disease. Community Eye Health Journal 1999.

6. State of the World's Sight 2020: The Right to Sight 1999 $-2005$.

7. Ayed T, Sokkah M, Charfi O, El Matri. L Epidemiological study of refractive errors in school children in socioeconomically deprived regions in Tunisia. J Fr Ophthalmology 2002 25 712-717.

8. Gruning Carl F. Pre-school screenings: Are they enough? Optometric Management 2001.

9. Leat SJ, Shute RH, Westall CA. Assessing Children's Vision: A Handbook.England, Butterworth Heinemann, 1999.

10. Naidoo KS, Raghunandan A, Mashige KP, Govender P, Holden BA, Pokeral GP, Ellwein LB. Refractive error and visual impairment in African children in South Africa. Invest Ophthal Vis Sci 2003 44(9) 3764-70.

11. School Health Policy and Implementation Guidelines. The Department of Health, 2003

12. Statistics South Africa: Census 2001. Published in 2006 Online http://www.statssa.gov.za/census01/html/default.asp.

13. Naidoo KS. Design of a Blindness Prevention Reporting and Planning Tool Utilizing the Results of a Population-based Study of Visual Impairment in a Health District in KwaZuluNatal. PHD Thesis at The University of New South Wales, Australia. 2009.

14. Guidelines for the Implementation of Eye Care Services. The National Department of Health, 2004.

15. Mills A. Mass campaigns versus general health services: what have we learnt in 40 years about vertical versus horizontal approaches? Bulletin of the World Health Organisation 2005 83(4) Geneva.

16. Naidoo KS, Govender P. Case finding in the clinic: Refractive Errors. Comm Eye Health J 200215 39-40. 